\title{
MODEL PROBLEM BASED LEARNING
}

MENINGKATKAN PEMAHAMAN KONSEP SISWA

\section{KELAS VII DITINJAU DARI HABIT OF STRIVING FOR ACCURACY AND PRECISION}

\author{
Nur Wahidin Ashari ${ }^{1}$, Salwah ${ }^{2}$, Kadek Widiani ${ }^{3}$ \\ Universitas Cokroaminoto Palopo ${ }^{1,2,3}$ \\ Email: nurwahidinashari@uncp.ac.id ${ }^{1}$, salwah@uncp.ac.id ${ }^{2}$
}

\begin{abstract}
Abstrak, Jenis penelitian yang digunakan adalah penelitian eksperimen dengan tujuan penelitian adalah untuk mengetahui: (1) perbedaan pemahaman konsep matematis antara siswa yang mendapatkan pembelajaran melalui model Problem Based Learning dan siswa yang mendapatkan pembelajaran melalui model konvensional ditinjau dari habit of striving for accuracy and precision, (2) peningkatan kemampuan pemahaman konsep siswa yang mendapatkan pembelajaran melalui model problem based learning lebih baik daripada siswa yang mendapatkan pembelajaran melalui model konvensional, (3) kualitas peningkatan kemampuan pemahaman konsep siswa yang mendapatkan pembelajaran melalui problem based learning dan siswa yang mendapatkan pembelajaran melalui model konvensional. Penelitian ini dilaksanakan di kelas VIIA dan VIIB SMP Negeri 3 Palopo, pada semester genap tahun ajaran 2019/2020. Populasi penelitian yaitu seluruh siswa kelas VII pada sekolah tersebut. Kemampuan kecakapan matematis yang dimaksud dalam penelitian ini adalah kemampuan siswa dalam memahami konsep dengan baik. Instrumen penelitian yang digunakan untuk mengumpulkan data dalam penelitian ini adalah Tes kemampuan pemahaman konsep matematis dan Angket Habits of Striving for Accuracy and Precision (HSAP). Teknik analisis data yang digunakan yaitu secara deskriptif dan inferensial dengan uji-t dan anova dua jalur. Hasil yang diperoleh dari penelitian ini adalah: (1) peningkatan pemahaman konsep matematis siswa kelas VII SMP Negeri 3 Palopo yang diajar dengan model pembelajaran PBL lebih baik daripada peningkatan pemahaman konsep matematis siswa yang diajar dengan model konvensional. Baik secara deskriptif maupun secara inferensial. (2) peningkatan kemampuan pemahaman konsep matematis siswa yang diajar dengan menggunakan model PBL memiliki kualitas peningkatan yang dikategorikan tinggi, sedangkan kualitas peningkatan kemampuan pemahaman konsep matematis yang diajar dengan model konvensional dikategorikan sedang.
\end{abstract}

\section{Kata Kunci: Problem Based Learning, Pemahaman Konsep matematis, Habit of Striving for Accuracy and Precision}

\begin{abstract}
The type of research used is experimental research with the aim of research is to find out: (1) differences in understanding of mathematical concepts between students who get learning through the Problem Based Learning model and students who get learning through conventional models in terms of habit of striving for accuracy and precision, (2) the increase in the conceptual understanding of students who get learning through the problem-based learning model is better than students who get learning through conventional models, (3) the quality of the increase in the conceptual understanding of students who get learning through problem-based learning and students who get learning through conventional models. This research was conducted in classes VIIA and VIIB SMP Negeri 3 Palopo, in the even semester of the 2019/2020 school year. The study population was all grade VII students at the school. The mathematical skills referred to in this study are the students' ability to understand concepts well. The research instruments used to collect data in this study were the ability to understand mathematical concepts and the Habits of Striving for Accuracy and Precision (HSAP) Questionnaire. The data analysis technique used is descriptive and inferential with t-test and two-way ANOVA. The results obtained from this study are: (1) the increase in the understanding of the mathematical concepts of the seventh grade students of SMP Negeri 3 Palopo who are taught using the PBL learning model is better than the increase in the understanding of the mathematical concepts of students taught with the conventional model. Both descriptively and inferentially. (2) the increase in the ability to understand mathematical concepts of students taught by using the PBL model has a high quality category of improvement, while the quality of the increase in the ability to understand mathematical concepts taught by conventional models is categorized as moderate.
\end{abstract}




\section{Keywords: Problem Based Learning, Understanding of Mathematical Concepts, Habit of Striving for Accuracy and Precision}

\section{A. Pendahuluan}

Pada abad 21 ini, Negara kita Indonesia membutuhkan sumber daya manusia (SDM) yang unggul dan berdaya saing internasional untuk meningkatkan kemajuan bangsa dan negara. Kualitas peserta didik yang dibutuhkan oleh bangsa Indonesia adalah yang mampu bersaing dengan ketat bersama dengan peserta didik dari bangsa lain di dunia. Hal ini dikarenakan perkembangan zaman yang selalu berubah dengan cepat dari tahun ke tahun. Faktor yang mendukung dan menentukan kemajuan pendidikan dan kualitas peserta didik adalah guru. Guru yang dihasilkan dari suatu perguruan tinggi adalah seseorang yang akan menjadi tombak atau garda terdepan bagi keberhasilan sumber daya manusia. Di era revolusi industry 4.0 ini keberadaan guru tidak bisa tergantikan. Guru di era ini harus mampu menguasai ilmu pengetahuan dan teknologi, agar dapat menghasilkan SDM yang unggul dengan kompetensi global.

Masa ini dinamakan era disrupsi teknologi. Informasi tersedia di mana saja dan kapan saja; komputasi lebih cepat memakai mesin; serta komunikasi dari mana saja dan ke mana saja. Kemampuan dan kehebatan teknologi tidak diragukan lagi, segala macam telepon pintar, aplikasi pintar, dan cepat bermunculan menggantikan kekuatan manusia. Teknologi menyebabkan pekerjaan yang sulit akan menjadi lebih efisien dan efektif, serta prosedur yang prosesnya lama menjadi lebih cepat, dan sebagainya. Kesemuanya ini tidak dapat terjadi apabila seseorang tidak cakap dalam matematika (Salwah, 2019).

Menurut Allsopp, dkk (2017) terdapat Lima bagian dari kecakapan matematis yang digambarkan oleh National Research Council pada tahun 2001 yaitu penalaran adaptif, kompetensi strategis, pemahaman konseptual, disposisi produktif, dan kelancaran prosedural. Terdapat lima standar proses yang menggambarkan caranya siswa harus mempelajari konten matematika yang diuraikan oleh National Council of Teachers of Mathematics pada 2000 yaitu pemecahan masalah, penalaran dan pembuktian, komunikasi, koneksi, dan representasi. Lima bagian kecakapan matematis dan lima standar proses untuk menciptakan delapan praktik matematika yang disebut mathematical habits of mind yang diuraikan oleh National Governors Association Center for Best Practices \& Council of Chief State School Officers pada tahun 2010 diantaranya (1) memahami masalah dan tekun dalam memecahkan, (2) alasan secara abstrak dan kuantitatif, (3) membangun argumen yang layak dan mengkritik alasan orang lain, (4) model dengan matematika, (5) gunakan alat yang sesuai secara strategis, (6) hadir untuk ketelitian, (7) mencari dan memanfaatkan struktur, (8) mencari dan mengungkapkan keteraturan dalam penalaran berulang. Berikut ini digambarkan hubungan diantara ketiganya.

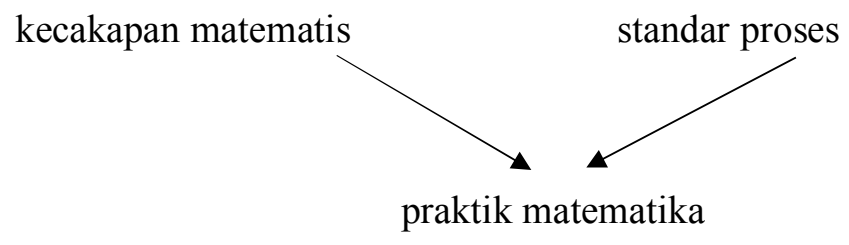

Gambar 1. Hubungan kecakapan matematis dan standar proses

Siswa harus dibiasakan untuk berpikir. Kebiasaan berpikir (habits of mind) adalah kebiasaan yang orang-orang lakukan saat berhadapan dengan suatu masalah. Kebiasaan berpikir adalah pola perilaku intelektual yang produktif (Lim, 2013). Kebiasaan berpikir kritis harus dilatih kepada siswa agar menjadi manusia yang intelektual. Seseorang yang intelektual tidak hanya memiliki informasi tetapi juga harus mengetahui apa yang akan dilakukan terhadap informasi tersebut. Kebiasaan berpikir akan melatih siswa kita lebih produktif, kritis, kreatif, 
tekun, dan memiliki wawasan yang luas. Ada begitu banyak kebiasaan berpikir, salah satunya adalah kebiasaan selalu berjuang demi ketepatan dan ketelitian (habits of striving for accuracy and precision). Seseorang yang cakap matematika, maka pasti memiliki tingkat ketepatan dan ketelitian yang baik. Hal ini didukung oelh pendapat Allsopp, dkk (2017) yang menyatakan kecakapan matematis dan standar proses dapat menciptakan dan meningkatkan ketelitian seseorang.

Menurut Boyes \& Watts (2009) menyebutkan jenis-jenis dari habit of striving for accuracy and precision (HSAP) diantaranya (1) Pakar (ahli): Tanpa disadari kompeten, (2) Pengguna: Sadar kompeten, (3) Pelajar: Sadar tidak kompeten, dan (4) Pemula: Tanpa sadar tidak kompeten. Pakar (ahli) yaitu seseorang yang Selalu memeriksa keakuratan dan ketepatan tanpa diminta; selalu memiliki perhatian yang besar terhadap pekerjaan, proyek, tugas, atau penilaian; memastikan semua pekerjaan selesai dengan tidak melakukan kesalahan, menetapkan standar tinggi dalam semua bidang kehidupan sekolah nya (akademik, atletik, kreatifitas); berusaha untuk memenuhi atau melebihi harapan di semua bidang. Pengguna yaitu Memeriksa pekerjaan agar lebih akurat; memerlukan waktu dan lebih peduli untuk memeriksa pekerjaannya sehingga terlepas dari kesalahan; menetapkan standar yang tinggi untuk menghasilkan pekerjaan yang akurat dan mempertahankan standar tersebut. Pelajar yaitu Mulai memeriksa pekerjaan yang salah dan memperbaiki kesalahan tersebut ketika diminta oleh guru, menunjukkan beberapa perbaikan saat menyerahkan pekerjaan dan menunjukkan bahwa beberapa langkah perbaikan telah diambil untuk lebih akurat dan tepat. Pemula yaitu Tidak dapat dan tidak akan melihat kesalahan dalam pekerjaannya; melakukan pekerjaan dengan tidak lengkap, tidak benar, dan ceroboh; tidak memanfaatkan waktu untuk meninjau kembali pekerjaan (memperbaiki kesalahan) (Boyes \& Watts, 2009).

Menurut Nafiah, Y, N (2014) penerapan model PBL dalam pembelajaran materi perbaikan dan setting ulang PC dapat meningkatkan keterampilan berpikir kritis siswa dalam pembelajaran. Menurut Paul R, \& Elder L (2008) berpikir kritis artinya menerapkan standar intelektual pada setiap unsur penalaran untuk menciptakan suatu sifat intelektual, yang lebih jelasnya ditunjukkan pada gambar di bawah ini.

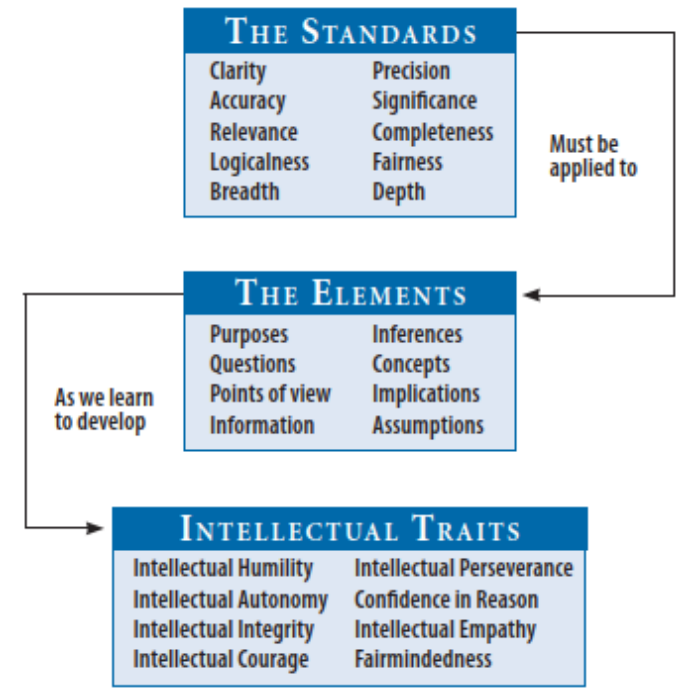

Gambar 2. Alur terciptanya suatu sifat intelektual dari kemampuan berpikir

Model pembelajaran yang mampu meningkatkan kemampuan kecakapan matematis siswa adalah Problem Based Learning (PBL), siswa dihadapkan permasalahan-permasalahan kontekstual kemudian siswa dituntut untuk menyelesaikan masalah-masalah tersebut. Model pembelajaran PBL tidak dirancang untuk membantu guru memberikan informasi sebanyakbanyaknya kepada siswa seperti pada pembelajaran langsung dan ceramah, tetapi Model 
pembelajaran PBL dikembangkan untuk membantu siswa mengembangkan kemampuan berpikir, mengembangkan kemampuan pemecahan masalah, keterampilan intelektual, dan menjadi siswa yang mandiri.

Berdasarkan uraian di atas maka peneliti tertarik untuk melakukan penelitian dengan tujuan yaitu untuk mengetahui: (1) perbedaan pemahaman konsep matematis antara siswa yang mendapatkan pembelajaran melalui model Problem Based Learning dan siswa yang mendapatkan pembelajaran melalui model konvensional ditinjau dari habit of striving for accuracy and precision, (2) peningkatan kemampuan pemahaman konsep siswa yang mendapatkan pembelajaran melalui model problem based learning lebih baik daripada siswa yang mendapatkan pembelajaran melalui model konvensional, (3) kualitas peningkatan kemampuan pemahaman konsep siswa yang mendapatkan pembelajaran melalui problem based learning dan siswa yang mendapatkan pembelajaran melalui model konvensional.

\section{B. Metode Penelitian}

Berdasarkan latar belakang dan rumusan masalah yang diuraikan di atas, penelitian ini dikategorikan sebagai penelitian kuantitatif. Jenis penelitian yang digunakan adalah penelitian eksperimen. Penelitian ini dilaksanakan di kelas VII A dan VII B SMP Negeri 3 Palopo, pada semester genap tahun ajaran 2019/2020. Populasi penelitian yaitu seluruh siswa kelas VII pada sekolah tersebut. Kemampuan kecakapan matematis yang dimaksud dalam penelitian ini adalah kemampuan siswa dalam memahami konsep dengan baik. Habit of striving for accuracy and precision (HSAP) yang dimaksudkan dalam penelitian ini ada dua yaitu (1) Pengguna: Sadar kompeten, dan (2) Pelajar: Sadar tidak kompeten.

Penelitian ini memberikan pembelajaran di dua kelas berbeda yaitu kelas eksperimen dan kelas kontrol untuk meningkatkan kemampuan pemahaman konsep matematis siswa ditinjau dari habit of striving for accuracy and precision (HSAP). Adapun desain faktorial yang digunakan dalam penelitian ini disajikan dalam table berikut ini:

Tabel 1. Desain Faktorial $2 \times 2$

\begin{tabular}{|c|c|c|}
\hline $\begin{array}{l}\text { HSAP } \\
\text { Kelas }\end{array}$ & Eksperimen & Kontrol \\
\hline Pengguna & EkPen & KoPen \\
\hline Pelajar & EkPel & Kopel \\
\hline
\end{tabular}

Jenis Instrumen penelitian yang digunakan untuk mengumpulkan data dalam penelitian ini adalah Tes kemampuan pemahaman konsep matematis yang akan diberikan di awal pengajaran (pretest) serta di akhir pengajaran (posttest) dalam bentuk tes uraian yang relatif sama, Angket Habits of Striving for Accuracy and Precision (HSAP) yang akan diberikan di awal pengajaran. Teknik analisis data yang digunakan yaitu secara deskriptif dan inferensial dengan uji-t dan anova dua jalur. Hasil perhitungan gain kemudian diinterpretasikan untuk melihat kualitas peningkatan kemampuan matematis siswa dengan menggunakan klasifikasi sebagai berikut:

Tabel 2. Klasifikasi N-Gain

\begin{tabular}{cc}
\hline N-Gain & Interpretasi \\
\hline$g \geq 0,7$ & Tinggi \\
$0,3 \leq g<0,7$ & Sedang \\
$g<0,3$ & Rendah \\
\hline
\end{tabular}

taraf signifikansi yaitu $5 \%(\alpha=0,05)$ 
Jurnal Penelitian Matematika dan Pendidikan Matematika

ISSN 26158132 (cetak)

ISSN 26157667 (online)

\section{Hasil dan Pembahasan}

Hasil analisis angket habit of striving for accuracy and precision (HSAP) yang menunjukkan jumlah siswa untuk masing-masing kategori adalah sebagai berikut:

Tabel 3. Jumlah Siswa untuk Masing-Masing Kategori HSAP

\begin{tabular}{ccc}
\hline \multirow{2}{*}{ Kategori } & \multicolumn{3}{c}{ Jumlah siswa } \\
\cline { 2 - 3 } & Kelas PBL & Kelas Konvensinal \\
\hline Pengguna & 17 & 14 \\
Pelajar & 9 & 12 \\
\hline
\end{tabular}

Berdasarkan data pada tabel di atas dapat disimpulkan bahwa kategori yang paling dominan dimiliki di setiap kelas baik kelas yang diajarkan dengan model PBL maupun model konvensional adalah HSAP dengan kategori pengguna. Selanjutnya secara deskriptif perbandingan skor rata-rata peningkatan pemahaman konsep matematis siswa kelas PBL dan kelas Konvensional dapat dilihat pada gambar berikut:

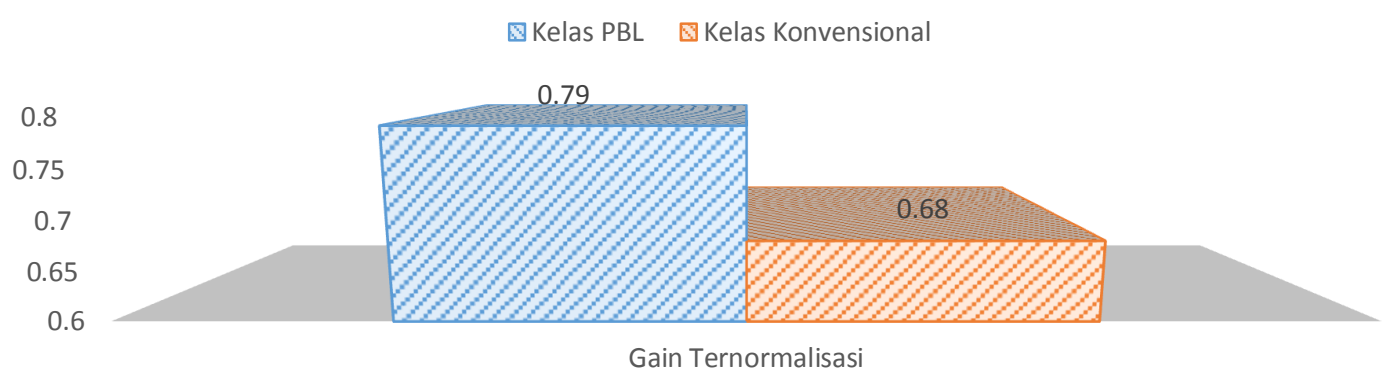

Gambar 3. Perbandingan Skor Rata-rata Peningkatan Kemampuan Pemahaman Konsep

Berdasarkan pada Gambar 3 di atas dapat disimpulkan bahwa secara deskriptif peningkatan kemampuan pemahaman konsep matematis siswa yang diajar dengan model PBL lebih baik daripada peningkatan kemampuan pemahaman konsep matematis siswa yang diajar dengan model konvensional. Pada tabel di bawah ini ditunjukkan secara deskriptif kualitas peningkatan kemampuan pemahaman konsep matematis pada kelas yang diajar dengan model PBL dan model konvensional. Selain itu berdasarkan hasil analisis data secara inferensial menggunakan uji-t, diperoleh nilai signifikansi 0.005 yang lebih kecil dari nilai $\alpha=0.05$ sehingga secara signifikan peningkatan pemahaman konsep matematis siswa kelas VII SMP Negeri 3 Palopo yang diajar dengan model pembelajaran PBL lebih baik daripada peningkatan pemahaman konsep matematis siswa yang diajar dengan model konvensional. Berikut ini dijabarakan kualitas peningkatan kemampuan pemahaman konsep matematis antara kelas yang diajar dengan model PBL dan model konvensional.

Tabel 4. Hasil Klasifikasi Gain Ternormalisasi pada Kedua Kelas yang Diajar

\begin{tabular}{cccc}
\hline Koefisien Normalisasi & \multicolumn{2}{c}{ Jumlah Siswa } & \multirow{2}{*}{ Klasifikasi } \\
\cline { 2 - 3 } Gain & PBL & Konvensional & \\
\hline $\mathrm{g}<0,3$ & 0 & 0 & Rendah \\
$0,3 \leq \mathrm{g}<0,7$ & 6 & 16 & Sedang \\
$\mathrm{g} \geq 0,7$ & 20 & 10 & Tinggi \\
\hline
\end{tabular}

Bila melihat Tabel 4 di atas dapat dikatakan bahwa klasifikasi peningkatan kemampuan pemahaman konsep matematis siswa yang diajar dengan menggunakan model PBL memiliki kualitas peningkatan yang dikategorikan tinggi, sedangkan kualitas peningkatan kemampuan pemahaman konsep matematis yang diajar dengan model konvensional dikategorikan sedang. Hal ini dikarenakan siswa yang diajar dengan model PBL memiliki motivasi dan kemandirian 
dalam menyelesaikan masalah yan diberikan. Hal ini sejalan dengan pendapat Ashari (2018) yang menemukan bahwa PBL memiliki implikasi terhadap suasana belajar siswa. Ashari menemukan bahwa model PBL akan menciptakan situasi di mana siswa akan belajar untuk menyelesaikan tugasnya secara mandiri. Hasil penelitiannya menyebutkan bahwa kemandirian belajar siswa dalam pemecahan masalah siswa dapat ditingkatkan dengan pembelajaran berbasis masalah.

Adapun perbandingan skor rata-rata kemampuan pemahaman konsep matematis siswa ditinjau dari HSAP dapat dilihat pada gambar di bawah ini.

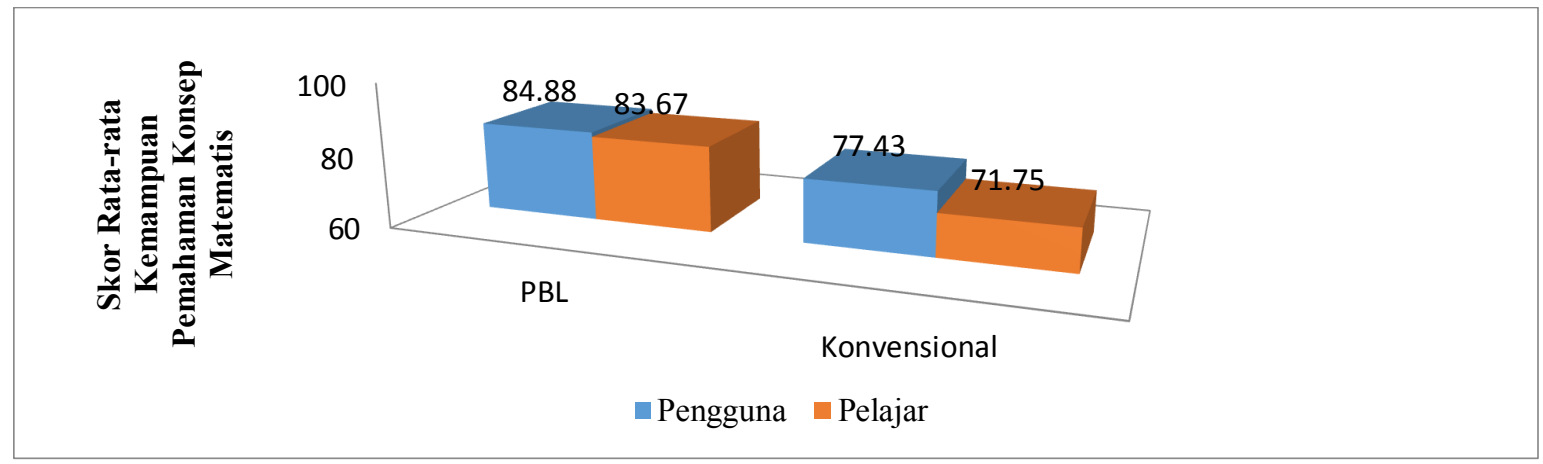

Gambar 4. Perbandingan Skor Rata-rata Kemampuan Pemahaman Konsep Siswa dengan Jenis HSAP Pengguna dan Pelajar pada masing-masing kelas

Berdasarkan Gambar 4 di atas menunjukkan bahwa secara deskriptif siswa yang HSAP dikategorikan pengguna memiliki kemampuan pemahaman konsep yang lebih baik daripada siswa dengan HSAP yang dikategorikan pelajar. Baik pada kelas yang diajar dengan model PBL maupun yang diajar dengan model konvensional. Sedangkan perbandingan skor rata-rata kemampuan pemahaman konsep antara siswa yang diajar denan model PBL dan model konvensional ditinjau dari HSAP siswa dapat dilihat pada diagram di bawah ini.

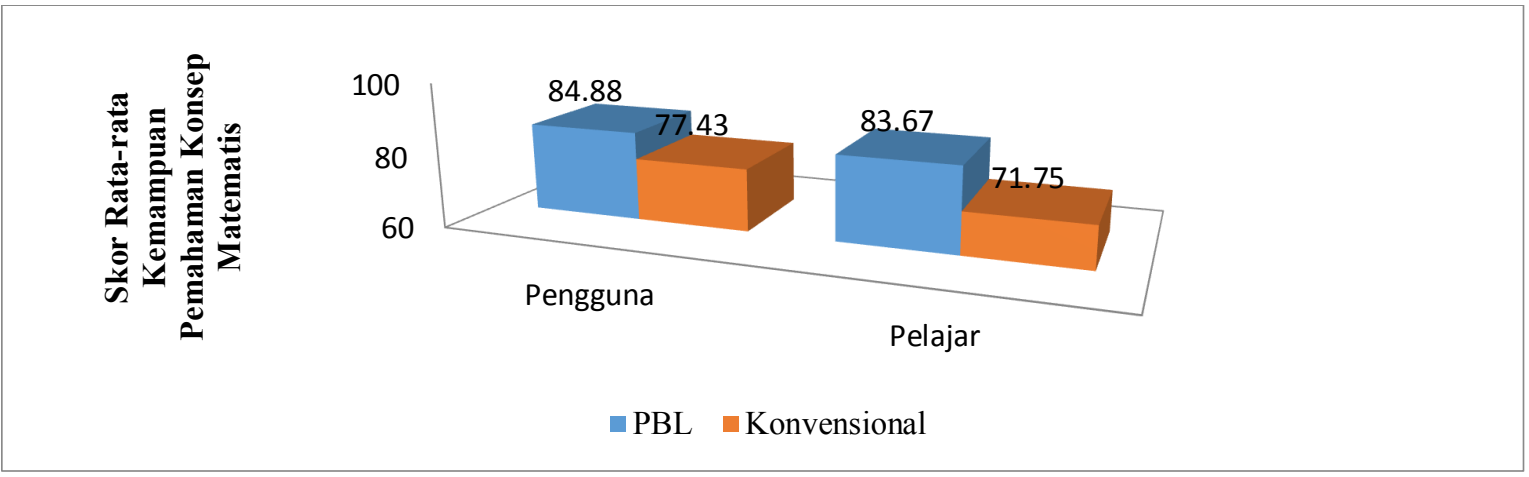

Gambar 5. Perbandingan Skor Rata-rata Kemampuan Pemahaman Konsep Siswa untuk setiap kelas dengan Jenis HSAP Pengguna dan Pelajar

Berdasarkan Diagram 5 di atas, dapat dikatakan bahwa kemampuan pemahaman konsep siswa dengan HSAP pengguna yang diajar dengan model PBL lebih baik daripada pemahaman konsep HSAP pengguna yang diajar dengan model konvensional. Begitupun dengan kategori pelajar pada kedua kelas tersebut. Hal ini dapat disebabkan karena siswa yang diajar dengan model PBL memiliki tingkat ketelitian yang lebih baik dari pada siswa yang diajar dengan model konvensional. Menurut Nafiah, Y, N (2014) penerapan model PBL dalam pembelajaran materi perbaikan dan setting ulang PC dapat meningkatkan keterampilan berpikir kritis siswa, sedankan Paul R, \& Elder L (2008) menyatakan bahwa pemikir kritis secara rutin menerapkan 
standar clarity, precision, accuracy, significance, relevance, completeness, etc dalam setiap melakukan proses pemecahan masalah.

Berikut ini disajikan hasil analisis data secara inferensial terkait dengan kemampuan pemahaman konsep matematis.

Tabel 5. Hasil Analisis Two Way Anova

\begin{tabular}{lrrrrr}
\hline Source & \multicolumn{1}{c}{ Type III Sum of } & \multicolumn{1}{c}{ Mean } \\
Squares & df & \multicolumn{1}{c}{ Square } & \multicolumn{1}{c}{ F } & \multicolumn{1}{c}{ Sig. } \\
\hline Corrected Model & $1428.614^{\mathrm{a}}$ & 3 & 476.205 & 3.819 & .016 \\
Intercept & 310908.211 & 1 & 310908.21 & 2493.3 & .000 \\
& & & 1 & 15 & \\
HSAP & 146.385 & 1 & 146.385 & 1.174 & .284 \\
Kelas & 1155.584 & 1 & 1155.584 & 9.267 & .004 \\
HSAP $*$ Kelas & 61.341 & 1 & 61.341 & .492 & .486 \\
Error & 5985.443 & 48 & 124.697 & & \\
Total & 337181.000 & 52 & & & \\
Corrected Total & 7414.058 & 51 & & & \\
\hline
\end{tabular}

Berdasarkan Tabel 5 di atas dapat digambarkan bahwa secara signifikan tidak terdapat pengaruh antara Habit of Striving for Accuracy and Precision terhadap kemampuan pemahaman konsep matematis siswa. Berdasarkan data di atas pula diperoleh bahwa terdapat pengaruh antara model pembelajaran terhadap kemampuan pemahaman konsep matematis siswa hal ini terlihat dari nilai sig sebesar 0.004 yang lebih kecil dari nilai $\alpha=0.05$, namun tidak terdapat interaksi antara antara HSAP dan model pembelajaran terhadap kemampuan pemahaman konsep matematis siswa, hal ini ditunjukkan dari hasil uji two way anova yang memperoleh nilai sig sebesar 0.486 yang lebih besar dari nilai $\alpha=0.05$.

Berikut ini diberikan jawaban siswa terkait salah satu indikator pemahaman konsep siswa yang diajar dengan model PBL.

Soal Pretes:

Anisa membeli 8 buku tulis dengan harga Rp.24.000,- dan 5 pulpen seharga Rp.10.000,-. Jika Anisa akan menjual kembali dan mendapatkan keuntungan. Berikan contoh harga 1 buku tulis dan 1 pulpen untuk dijual kembali?

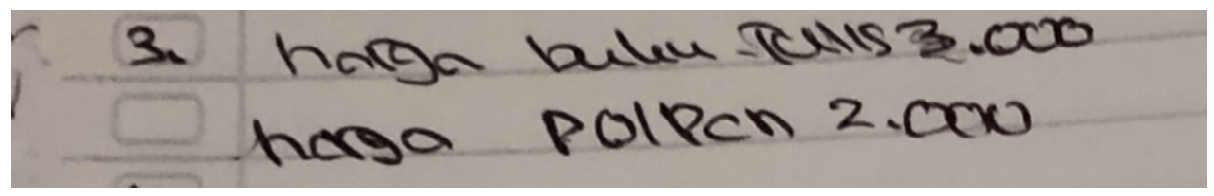

Gambar 6. Jawaban pretest pemahaman konsep siswa pada indikator memberikan contoh dan

Soal postes: non contoh dari konsep

Anisa membeli 6 buku tulis dengan harga Rp.24.000,- dan 3 pulpen seharga Rp.15.000,-. Jika Anisa akan menjual kembali dan mendapatkan keuntungan. Berikan contoh harga 1 buku tulis dan 1 pulpen untuk dijual kembali? 


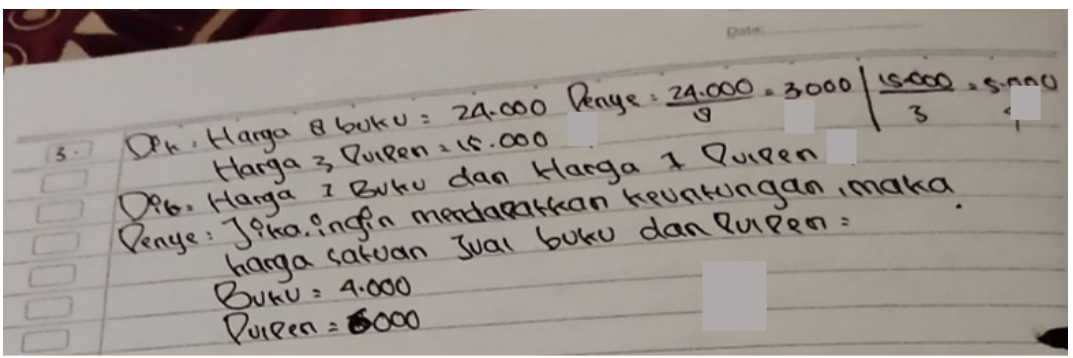

Gambar 7. Jawaban posttest pemahaman konsep siswa pada indikator memberikan contoh dan non contoh dari konsep

Berdasarkan gambar 6 di atas dapat terlihat bahwa jawaban siswa menunjukkan harga 1 buah pulpen dan 1 buah buku yang bila dijual kembali maka akan kembali modal namun tidak mengalami keuntungan. Bila melihat jawaban siswa ini, terlihat bahwa siswa belum memahami maksud dari permintaan soal, yang meminta siswa menyebutkan satu contoh harga penjualan sebuah buku tulis dan pulpen agar memperoleh keuntungan, Setelah siswa memperoleh pembelajaran dengan model PBL, maka pemhaman konsep siswa semakin baik, hal ini terlihat dari jawaban siswa pada ggambar 7 di atas. Hal ini disebabkan karena setiap pertemuan pada kelas yan diajar dengan model PBL selalu diberikan masalah yang tertuang dalam lembar kerja siswa. Menurut Ma'rufi, dkk (2019) yang menyatakan bahwa LKS dirancang agar siswa dapat bekerja secara mandiri tanpa bantuan langsung dari guru.

\section{Kesimpulan}

Berdasarkan hasil analisis data dan pembahasan maka diperoleh kesimpulan (1) peningkatan pemahaman konsep matematis siswa kelas VII SMP Negeri 3 Palopo yang diajar dengan model pembelajaran PBL lebih baik daripada peningkatan pemahaman konsep matematis siswa yang diajar dengan model konvensional. Baik secara deskriptif maupun secara inferensial. (2) peningkatan kemampuan pemahaman konsep matematis siswa kelas VII SMP Negeri 3 Palopo yang diajar dengan menggunakan model PBL memiliki kualitas peningkatan yang dikategorikan tinggi, sedangkan kualitas peningkatan kemampuan pemahaman konsep matematis yang diajar dengan model konvensional dikategorikan sedang. (3) tidak terdapat pengaruh antara Habit of Striving for Accuracy and Precision terhadap kemampuan pemahaman konsep matematis siswa kelas VII SMP Negeri 3 Palopo. (4) terdapat pengaruh antara model pembelajaran terhadap kemampuan pemahaman konsep matematis siswa. (5) tidak terdapat interaksi antara antara HSAP dan model pembelajaran terhadap kemampuan pemahaman konsep matematis siswa kelas VII SMP Negeri 3 Palopo.

\section{DAFTAR PUSTAKA}

Allsopp, dkk (2017). Supporting Mathematical Proficiency Strategies for New Special Education Teachers. Teaching Exceptional Children, Vol. 49, No. 4, pp. 273-283. Copyright 2017 The Author(s). DOI: 10.1177/0040059917692112.

Ashari (2018). Problem Based Learning untuk Meningkatkan Self Directed Learning dalam Pemecahan Masalah Mahasiswa Calon Guru: Suatu Studi Literatur. Proximal: Jurnal Penelitian Matematika dan Pendidikan Matematika Vol 1 Nomor 1.

Boyes, \& Watts. (2009). Developing Habits of Mind in Secondary Schools. Virginia: Association for Supervision and Curriculum Development (ASCD). 
Kilpatric Swafford, J., \& Findell, B. (Eds.). (2001). Adding it up: Helping children learn mathematics. Washington, DC: National Academy Press.

Lim, K. (2013). General and Mathematical Habits of Mind: An Overview. San Diego: University of Texas at El Paso.

Ma'rufi, M Ilyas, RF Pasandaran, Salwah. (2019). Exploration of teachers'"knowledge of students" in study-based teaching on polyhedron material. Journal of Physics: Conference Series, Vol 1397 (1) Page 012088.

Nafiah, Y, N. (2014). Penerapan Model Problem-Based Learning untuk Meningkatkan Keterampilan Berpikir Kritis dan Hasil Belajar Siswa. Jurnal Pendidikan Vokasi. Vol 4, Nomor 1, Februari 2014.

Paul, R., \& Elder, L. (2008). Miniature guide to critical thinking concepts and tools. Dillon Beach: Foundation for Critical Thinking Press. www.criticalthinking.org.

Salwah \& Ashari, N.W. 2019. Students' Mathematical Proficiency in Solving Generating Function and Recurrence Relation in Discrete Mathematics Course. International Conference on Natural and Social Sciences (ICONSS) Proceeding Series, 257-261. 